\title{
Three-dimensional deformation time series of glacier motion from multiple-aperture DInSAR observation
}

\author{
Sergey Samsonov ${ }^{1}[$
}

Received: 22 March 2019 / Accepted: 10 November 2019 / Published online: 22 November 2019

(c) The Author(s) 2019

\begin{abstract}
The previously presented Multidimensional Small Baseline Subset (MSBAS-2D) technique computes two-dimensional (2D), east and vertical, ground deformation time series from two or more ascending and descending Differential Interferometric Synthetic Aperture Radar (DInSAR) data sets by assuming that the contribution of the north deformation component is negligible. DInSAR data sets can be acquired with different temporal and spatial resolutions, viewing geometries and wavelengths. The MSBAS-2D technique has previously been used for mapping deformation due to mining, urban development, carbon sequestration, permafrost aggradation and pingo growth, and volcanic activities. In the case of glacier ice flow, the north deformation component is often too large to be negligible. Historically, the surface-parallel flow (SPF) constraint was used to compute the static three-dimensional (3D) velocity field at various glaciers. A novel MSBAS-3D technique has been developed for computing 3D deformation time series where the SPF constraint is utilized. This technique is used for mapping 3D deformation at the Barnes Ice Cap, Baffin Island, Nunavut, Canada, during January-March 2015, and the MSBAS-2D and MSBAS-3D solutions are compared. The MSBAS-3D technique can be used for studying glacier ice flow at other glaciers and other surface deformation processes with large north deformation component, such as landslides. The software implementation of MSBAS-3D technique can be downloaded from http://insar.ca/.
\end{abstract}

Keywords Three-dimensional deformation · DInSAR · MSBAS · Barnes Ice Cap · Glacier · RADARSAT-2

\section{Introduction}

Differential Interferometric Synthetic Aperture Radar (DInSAR) maps ground deformation with high spatial resolution and precision over large areas in line of sight (LOS) of the sensor. Hence, the signal is the weighted linear combination of the three (north, east and vertical) deformation components equal to the projection of the deformation vector on the satellite line of sight. In most common imaging geometries, the vertical component has the greatest weight and the north component has the least weight.

The three components of the deformation vector cannot be reconstructed from a single DInSAR measurement, so various techniques were developed to overcome this limitation (Hu et al. 2014; Fuhrmann and Garthwaite 2019). In rare cases (e.g., at high latitudes) 3D solution can be derived

Sergey Samsonov

sergey.samsonov@canada.ca

1 Canada Centre for Mapping and Earth Observation, Natural Resources Canada, 560 Rochester Street, Ottawa, ON K1A 0E4, Canada directly from three independent DInSAR observations (Gray 2011). The most common approach is to combine ascending and descending DInSAR measurements with either offset tracking (Raucoules et al. 2013) or multiple-aperture interferometry (MAI) (Jo et al. 2017) measurements, or both (Wang et al. 2018); or to utilize prior knowledge or an analytical model of the deformation process (Yang et al. 2018; Liu et al. 2018). However, the precision of offset tracking and MAI measurements is significantly lower than the precision of DInSAR and sufficiently detailed prior information is rarely available.

Another approach is to discard the contribution of the north deformation component (since it has the least weight), which reduces the problem to the 2D case that can be solved using only ascending and descending DInSAR data (Manzo et al. 2006; Motagh et al. 2017; Palanisamy Vadivel et al. 2019). This approach can be extended to produce $2 \mathrm{D}$ deformation time series when ascending and descending DInSAR data are acquired at precisely the same times. However, ascending and descending DInSAR data are usually acquired at different times and sometimes with different revisit fre- 
quencies (e.g., 24 days for RADARSAT- 2 and 6 days for Sentinel-1).

Fuhrmann and Garthwaite (2019) proposed to interpolate the DInSAR measurements to common epochs. The Multidimensional Small Baseline Subset (MSBAS-2D) technique was developed in order to overcome the need for interpolation. It combines several DInSAR data sets acquired at different times and with different frequencies to produce continuous 2D (east and vertical) deformation time series. To overcome the rank deficiency of the problem, Tikhonov zeroth-, first- or second-order regularization is used. The MSBAS-2D technique has already been used for mapping ground deformation due to mining (Samsonov et al. 2013a, b, 2014b), urban development (Samsonov et al. 2014a, 2016b; Samsonov d'Oreye 2017), carbon sequestration (Samsonov et al. 2015; Czarnogorska et al. 2016), permafrost aggradation and pingo growth (Samsonov et al. 2016a), and volcanic activities (Samsonov and d'Oreye 2012; Samsonov et al. 2014c, d, 2017).

For mapping glacier ice flow, the MSBAS-2D technique produces invalid results, particularly for the vertical deformation component. This happens because in the case of ice flow the north deformation component can reach values significantly larger than the vertical deformation component and therefore is no longer negligible.

The surface-parallel flow (SPF) constraint assumes that motion, driven by the gravitational force, is parallel to the tangent plane of the topography. This constraint provides the third equation, along with ascending and descending DInSAR measurements, necessary for calculating 3D deformation of glaciers at one instance of the time (here called the static case). This approach was used for mapping 3D deformation of Antarctic (Rignot et al. 2011), Greenland (Joughin et al. 1998; Mohr et al. 1998) and Himalayan (Kumar et al. 2011) glaciers and validated by independent GPS (Kumar et al. 2011) and MAI (Gourmelen et al. 2011) measurements.

In this paper, the SPF constraint is added to MSBAS to fully resolve all three deformation components (here called the MSBAS-3D technique). This approach is used for computing the 3D deformation time series for the Barnes Ice Cap, Baffin Island, Nunavut, Canada, for the period of JanuaryMarch 2015. Previous studies revealed that elevation loss at this glacier reached $2.7 \mathrm{~m}$ during the 2010-2014 period (Gray et al. 2015); this glacier is likely to disappear under current climate conditions within the next millennium (Gilbert et al. 2016).

\section{Methodology}

\subsection{MSBAS-2D}

The MSBAS-2D technique computes the approximate 2D (east and vertical) deformation time series from ascending and descending DInSAR data, acquired over the same area and time period by several sensors. In matrix form MSBAS2D can be written as

$$
\left(\begin{array}{c}
\hat{A} \\
\lambda L
\end{array}\right)\left(\begin{array}{c}
V_{\mathrm{E}} \\
V_{\mathrm{U}}
\end{array}\right)=\left(\begin{array}{c}
\hat{\Phi} \\
0
\end{array}\right)
$$

where the matrix $\hat{A}=\left\{s_{\mathrm{E}} A, s_{\mathrm{U}} A\right\}$ consists of the matrix $A$, constructed from the time intervals between consecutive SAR acquisitions and the east and vertical components of the line-of-sight vector $s=\left\{s_{\mathrm{E}}, s_{\mathrm{U}}\right\}=\{-\cos \theta \sin \phi, \cos \phi\}$, where $\theta$ is the azimuth angle and $\phi$ is the incidence angle of the sensor. The matrix $\hat{\Phi}$ represents the observed DInSAR data, geocoded and resampled to a common grid. The Tikhonov regularization matrix $L$ multiplied by the regularization parameter $\lambda$ is used for regularizing time series. The effect of regularization is similar to applying a low-pass filter; it removes the high-frequency atmospheric noise component of the signal. Regularization is required when the acquisition times of the ascending and descending data do not match. The explicit form of the matrix $A$, as well as the regularization matrices $L$ of zeroth, first and second orders, was explicitly derived in (Samsonov 2010; Samsonov d'Oreye 2017). The unknown east and vertical components of deformation velocities $V_{\mathrm{E}}$ and $V_{\mathrm{U}}$ for each acquisition epoch and pixel are solved by applying the singular value decomposition (SVD), and the deformation time series are reconstructed from the computed deformation velocities by numerical integration.

\subsection{MSBAS-3D}

In order to compute the precise 3D (north, east and vertical) deformation time series, three independent DInSAR data sets are required. However, normally only two sets of DInSAR data, from the ascending and descending orbits, are available. Therefore, the precise 3D solution cannot be computed unless supplementary data or a constraint is introduced. In the case of the glacier ice flow, as a first-order approximation, it can be assumed that ice slides parallel to the surface without undergoing internal deformation. The constraint describing such SPF motion (Joughin et al. 1998) can be written in terms of deformation velocities in the following form

$V_{\mathrm{U}}=\frac{\partial H}{\partial X_{\mathrm{N}}} V_{\mathrm{N}}+\frac{\partial H}{\partial X_{\mathrm{E}}} V_{\mathrm{E}}$

where $H$ is the topographic height and $\frac{\partial H}{\partial X_{\mathrm{N}}}$ and $\frac{\partial H}{\partial X_{\mathrm{E}}}$ are the first derivatives in the north $X_{\mathrm{N}}$ and east $X_{\mathrm{E}}$ directions.

The MSBAS-3D technique computes the constraint 3D deformation time series, which then can be written in a matrix 
form as

$$
\left(\begin{array}{c}
\hat{A} \\
H \\
\lambda L
\end{array}\right)\left(\begin{array}{c}
V_{\mathrm{N}} \\
V_{\mathrm{E}} \\
V_{\mathrm{U}}
\end{array}\right)=\left(\begin{array}{c}
\hat{\Phi} \\
0 \\
0
\end{array}\right)
$$

where the matrix $\hat{A}=\left\{s_{\mathrm{N}} A, s_{\mathrm{E}} A, s_{\mathrm{U}} A\right\}$ consists of the matrix A (described above) and the north, east and vertical components of the line-of-sight vector $s=\left\{s_{\mathrm{N}}, s_{\mathrm{E}}, s_{\mathrm{U}}\right\}=$ $\{\sin \theta \sin \phi,-\cos \theta \sin \phi, \cos \phi\}$. The matrix $H=\left\{\frac{\partial H}{\partial X_{\mathrm{N}}}\right.$, $\left.\frac{\partial H}{\partial X_{\mathrm{E}}},-1\right\}$ represents the SPF constraint. The unknown north, east and vertical components of deformation velocities $V_{N}$, $V_{\mathrm{E}}$ and $V_{\mathrm{U}}$ for each acquisition epoch and pixel are solved by applying SVD, and the deformation time series are reconstructed from the computed deformation velocities by numerical integration.

\subsubsection{MSBAS-3D for non-steady-state flow}

Equations (2) and (3) assume a steady-state condition where the ice slides parallel to the surface of the glacier. In the more general case, there is an additional component due to the elevation change between consecutive acquisitions; for example, the amount of ice removed by flow may exceed the amount of ice replenished by the precipitation, resulting in elevation change over time. This process is a non-steady state, and (2) can then be rewritten in the following form

$V_{\mathrm{U}}=V_{\mathrm{U}}^{\mathrm{nss}}+\frac{\partial H}{\partial X_{\mathrm{N}}} V_{\mathrm{N}}+\frac{\partial H}{\partial X_{\mathrm{E}}} V_{\mathrm{E}}$

where the additional term $V_{\mathrm{U}}^{\mathrm{nss}}$ is the component of the vertical velocity responsible for changes in surface elevation due to the non-steady-state flow (i.e., mass loss). The MSBAS$3 \mathrm{D}$ technique then computes the constraint 3D deformation time series in the case of the non-steady-state flow that can be written in a matrix form as

$$
\left(\begin{array}{c}
\hat{A} \\
H \\
\lambda L
\end{array}\right)\left(\begin{array}{c}
V_{\mathrm{N}} \\
V_{\mathrm{E}} \\
V_{\mathrm{U}}
\end{array}\right)=\left(\begin{array}{c}
\hat{\Phi} \\
-V_{\mathrm{U}}^{\mathrm{nss}} \\
0
\end{array}\right)
$$

The time- and space-dependent quantity $V_{\mathrm{U}}^{\text {nss }}$ must be derived from other remote sensing or in situ observations or modeling.

\section{Data}

From the available 64 ascending (January 2012-June 2018) and 68 descending (May 2012-June 2018) Wide-Fine RADARSAT-2 SAR images, only five ascending and four descending images were used in this study (Fig. 1). These

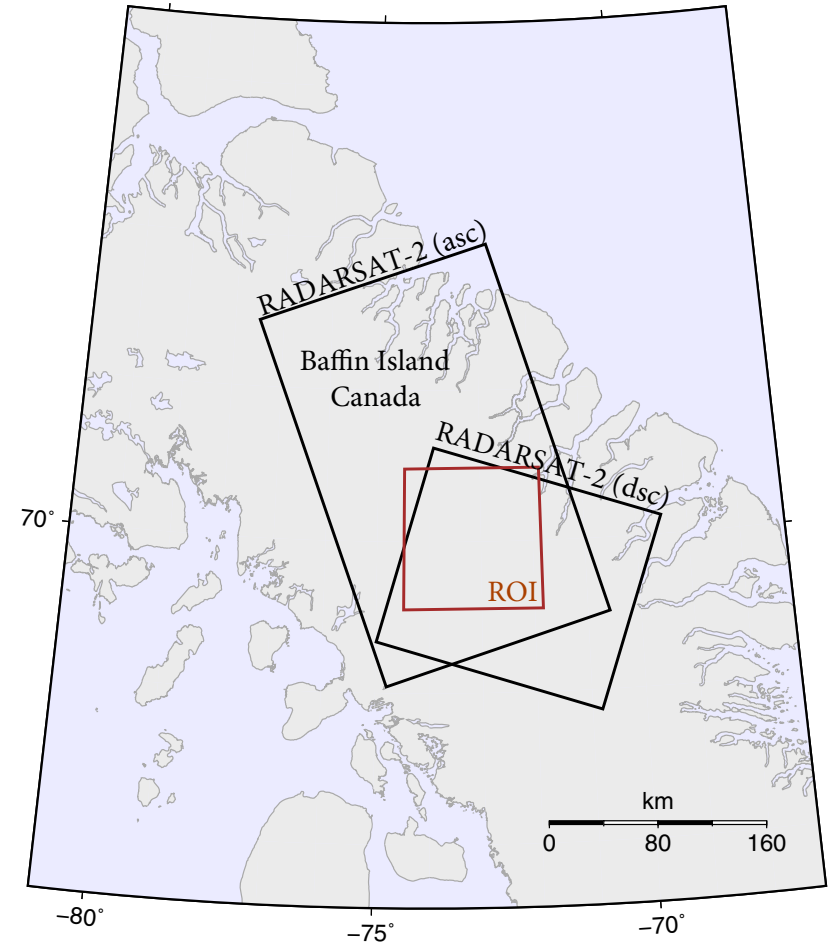

Fig. 1 Region of interests, Barnes Ice Cap, outlined in brown are located on Baffin Island (Canadian territory of Nunavut). RADARSAT2 ascending and descending Wide-Fine SAR images used in this study are outlined in black

images were acquired at 24-day revisit interval during January-March 2015 (Fig. 2c), when the surface temperature in the region was at its lowest seasonal range. During this period the ground remained frozen and the ice velocity remained low. Interferograms, produced from these nine images, exhibited better than average interferometric coherence making accurate phase unwrapping possible.

The original SAR data were acquired with a ground resolution of $4.7 \times 5.1 \mathrm{~m}$ over an area of $150 \times 150 \mathrm{~km}$ (Table 1 ). Two ascending frames were concatenated and processed together. Standard DInSAR analysis was performed using the GAMMA software. Multi-looking with a factor of 6 in range direction and 8 in azimuth direction was applied to achieve approximate square pixels and to reduce noise in the DInSAR data, resulting in a ground resolution of $40 \times 40 \mathrm{~m}$. The topographic phase was removed using ArcticDEM Digital Elevation Model (Fig. 2f) provided by the University of Minnesota. The downloaded segment of ArcticDEM contained several visible artifacts (i.e., very large values) northeast the region of interest that were manually corrected. In total seven interferograms were filtered, unwrapped and geocoded to a $40 \times 40 \mathrm{~m}$ grid over the common area. An example of wrapped ascending and descending interferograms is shown in Fig. 2d, e.

The central first derivative maps in the north (Fig. $2 \mathrm{~g}$ ) and east (Fig. 2h) directions were computed with the Generic 


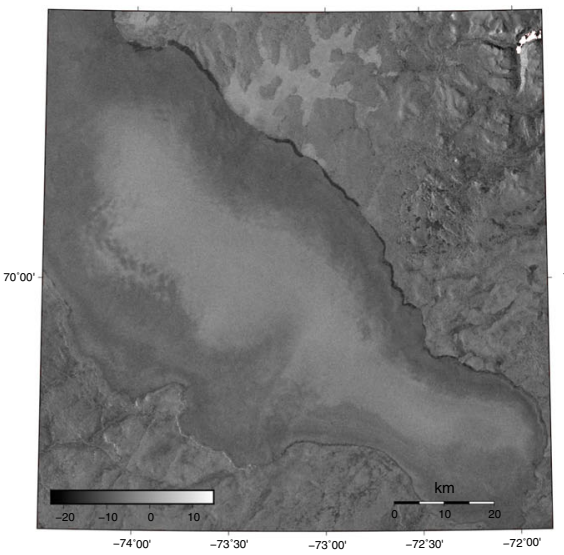

(a) SAR image 20141216 (asc)

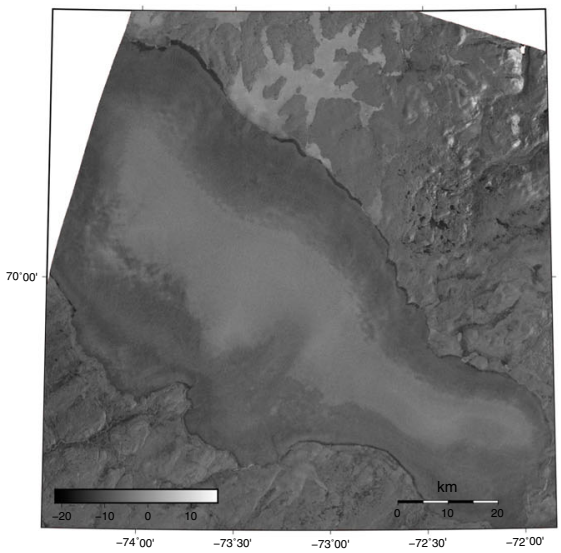

(b) SAR image 20150106 (dsc)

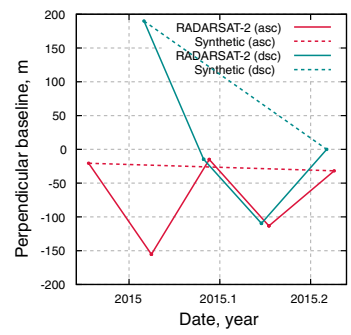

(c) Spatial and temporal baselines

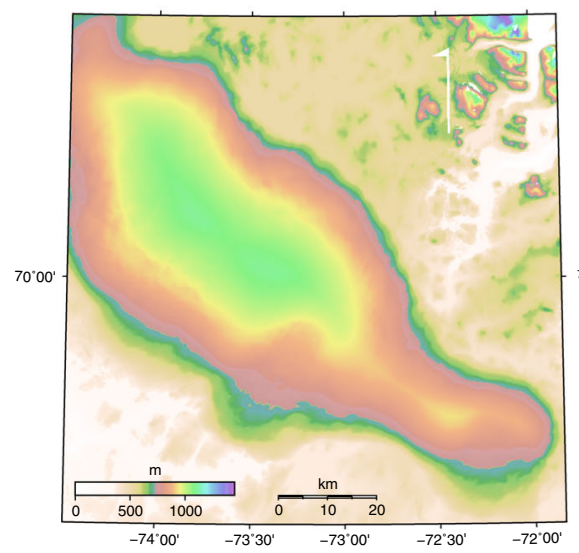

(f) Digital elevation model

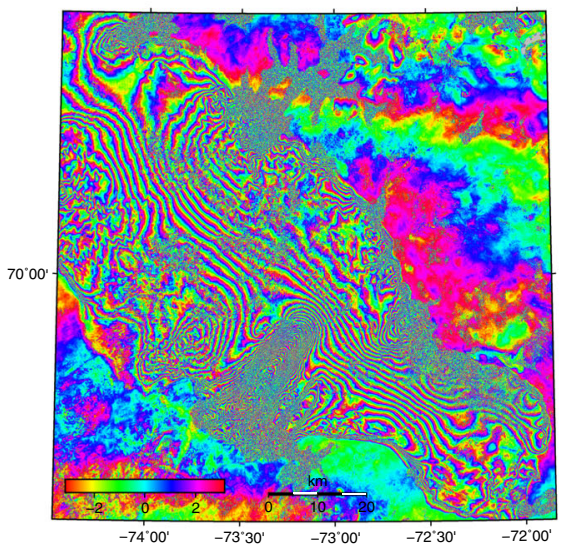

(d) Interferogram 20150109-20150202 (asc)



(g) First derivative along north direction

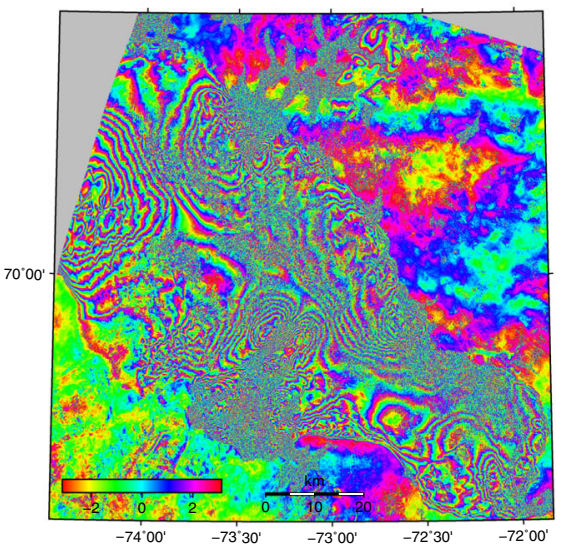

(e) Interferogram 20150106-20150130 (dsc)

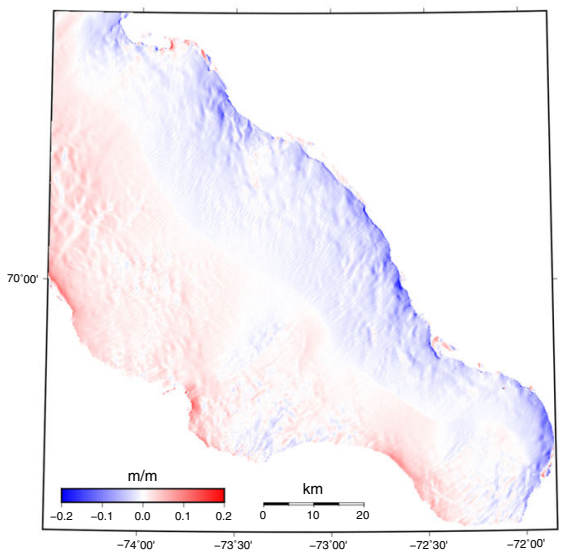

(h) First derivative along east direction
Fig. 2 Data used in this study: a, b typical SAR images; $\mathbf{c}$ spatial and temporal baselines of RADARSAT-2 (solid lines) and synthetic (dashed lines) ascending and descending interferograms; $\mathbf{d}$ typical ascending interferogram used in this study computed from SAR images acquired on January 9 and February 2, 2015; e typical descending interferogram used in this study computed from SAR images acquired on January 6 and 30, 2015; f resampled to 40-m resolution ArcticDEM; $\mathbf{g}$ central first derivative of DEM in north direction; $\mathbf{h}$ central first derivative of DEM in east direction 
Table 1 RADARSAT-2 Wide-Fine (FOW1) Synthetic Aperture Radar data used in this study, $\theta$ is azimuth angle and $\phi$ is incidence angle, $N$ is number of SLC images, and M is number of DInSAR interferograms computed for each data set

\begin{tabular}{llllll}
\hline DInSAR data set & $\theta$ & $\phi$ & Temporal coverage & $N$ & $M$ \\
\hline RADARSAT-2 (asc) & 339 & 26 & $20141216-20150322$ & 5 & 4 \\
RADARSAT-2 (dsc) & 197 & 26 & $20150106-20150319$ & 4 & 3 \\
Total & & & $20150106-20150319$ & 9 & 7 \\
\hline
\end{tabular}

Three-dimensional time series span January 6-March 19, 2015, interval when both ascending and descending data are available

Mapping Tools (GMT) command "grdmath DDX/DDY -M" from the same ArcticDEM that was used for removing the topographic phase during DInSAR processing.

The 2D and constrained 3D deformation time series were computed by applying MSBAS-2D and MSBAS-3D techniques with the first-order Tikhonov regularization (with $\lambda=0.1$ ), respectively. North, east and vertical components of linear deformation rates were computed by applying the linear regression to north, east and vertical components of deformation time series.

\subsection{Selecting optimal regularization parameter $\lambda$}

The regularization parameter $\lambda$ can be selected using the Lcurve method (Hansen and O'Leary 1993). For this, multiple solutions are computed with varying $\lambda \mathrm{s}$ and the norm of a regularized solution versus the norm of the corresponding residual norm (both quantities are computed by MSBAS$3 \mathrm{D}$ ) is plotted on a log-log plot. The optimal regularization parameter $\lambda$ is then located in the corner of the curve, which usually resembles the shape of the letter $\mathrm{L}$.

The L-curve method does not work well for the reconstruction of very smooth exact solutions (Hansen and O'Leary 1993) as is this case based on four ascending and three descending interferograms acquired consecutively. These Lcurves are shown in the top row of Fig. 3 for the zeroth-, first- and second-order Tikhonov regularization. The zerothorder curve (Fig. 3b) does not have a L-curve, while the two other curves (Fig. 3b, c) have poorly developed L-curves. The optimal $\lambda$ equal to 0.1 is selected from Fig. $3 b$.

The very smooth solutions are uncommon, however. In order to demonstrate that the L-curve method usually works, two synthetic interferograms were created and added to the input data set, as follows. The ascending interferogram was created by summing the four consecutive ascending interferograms, and the descending interferogram was computed by summing the three consecutive descending interferograms (dashed lines in Fig. 2c). White noise with the mean value of zero and the standard deviation of $0.02 \mathrm{~m}$ was added to both synthetic interferograms, and the solutions for multiple $\lambda \mathrm{s}$ were computed. The L-curves for this case are shown in the bottom row of Fig. 3. In this case, the shape of the L-curve is well defined and the optimal regularization parameter $\lambda$ can be easily selected.

\section{Results}

Computed with MSBAS-2D, two-dimensional east and vertical linear deformation rates with time series for three $5 \times 5$ pixels regions $\mathrm{P} 1-\mathrm{P} 3$ are shown in Fig. 4 . These small regions were arbitrary selected for demonstrating temporal variability of deformation. The stable area $R$ was manually selected outside the area of the expected surface motion, and all movements shown here are relative to the average movement in this area. The east component of the linear deformation rate shows eastward and westward motion with a magnitude of about $15 \mathrm{~m} /$ year. Ice on the western side of the glacier moves westward and ice on the eastern side moves eastward, as expected. The vertical component of the linear deformation rate shows that the western side of the glacier experiences upward motion and the eastern side experiences downward motion. Such deformation pattern, particularly upward motion of the western part of the glacier, is unexpected; it is a processing artifact that will be resolved by the MSBAS-3D technique.

Computed with MSBAS-3D, three-dimensional north, east and vertical linear deformation rates with time series for points P1-P3 are shown in Fig. 5. The east deformation component shows a similar pattern and rate as in the case of the $2 \mathrm{D}$ processing. The vertical deformation component now clearly shows downward motion throughout the entire glacier, with a magnitude of about $3 \mathrm{~m} / \mathrm{year}$. The north deformation component shows southern and northern motion with a magnitude of about $30 \mathrm{~m} / \mathrm{year}$ and the expected deformation pattern. The time series for points $\mathrm{P} 1-\mathrm{P} 3$ show motion with a nearly constant rate. A horizontal deformation rate vector map computed from north and east deformation rate components is shown in Fig. 5g.

Additional tests performed on complete sets of 2012-2018 64 ascending and 68 descending images (not shown here) demonstrated that ice flow velocity displays seasonal variability, but over an interval of four months, as found in this study (Fig. 5d-f), deformation rate remains nearly constant.

\subsection{Error analysis}

The random error produced by the noise in the input data cannot be directly estimated because the signal and noise cannot be separated. To indirectly estimate the precision of the computed deformation rates, white noise with a mean value of zero and standard deviations ranging from 0.001 to $0.025 \mathrm{~m}$ in increments of $0.0001 \mathrm{~m}$, was added to each interferogram and multiple solutions were computed. The standard deviations 


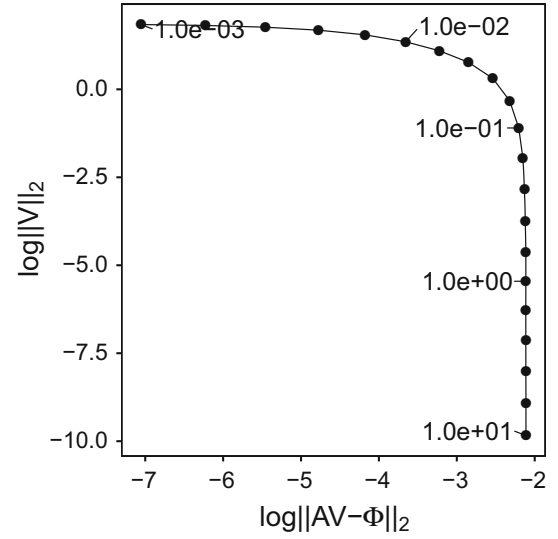

(a) Zeroth order

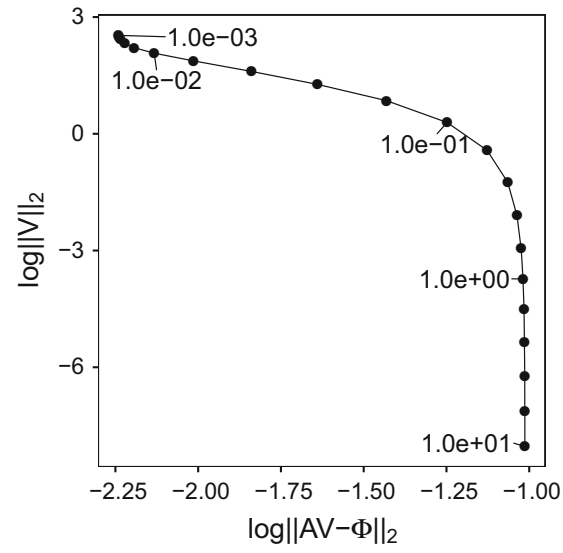

(d) Zeroth order (noisy)

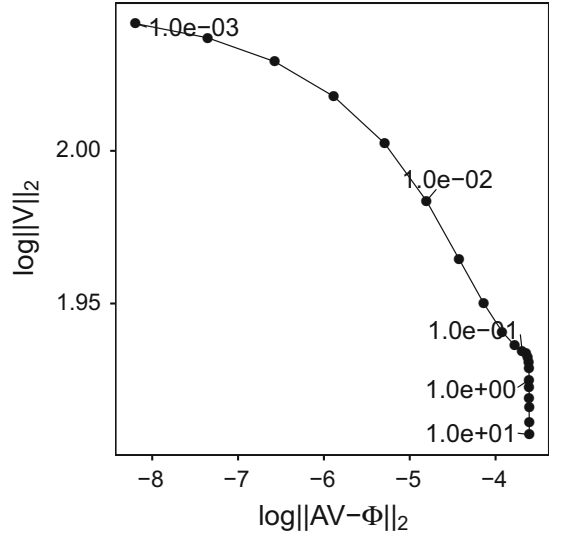

(b) First order

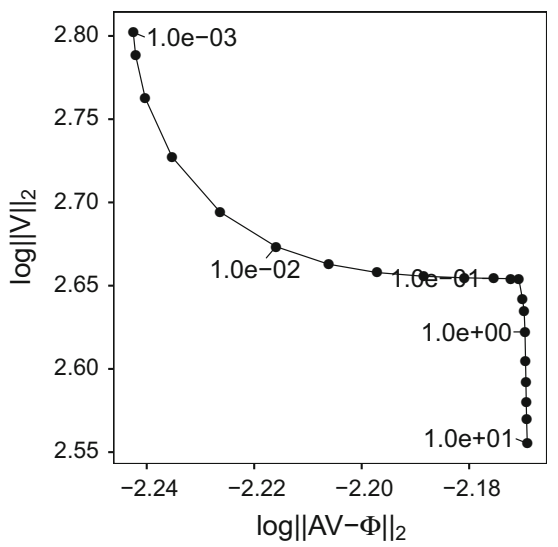

(e) First order (noisy)

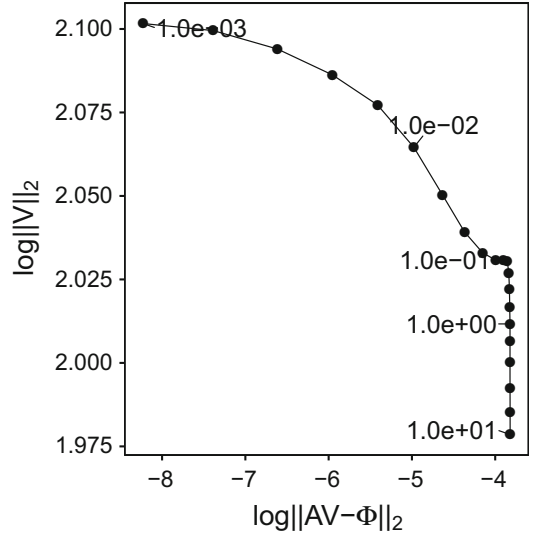

(c) Second order

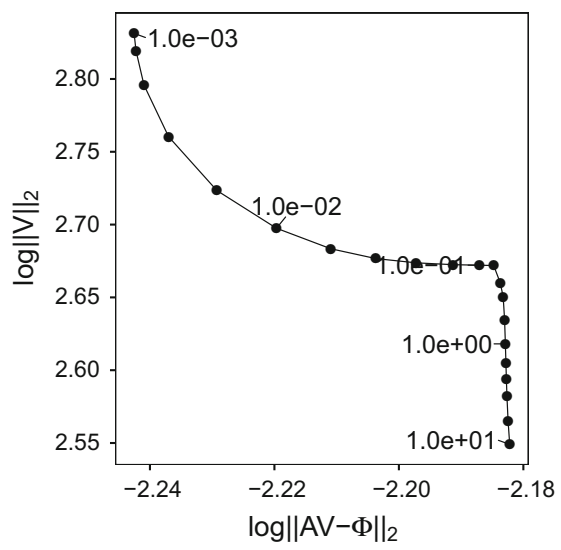

(f) Second order (noisy)

Fig. 3 L-curves for zeroth-, first- and second-order Tikhonov regularizations for the original (top row) and synthetic (bottom row) cases. Values of regularization parameter $\lambda$ in range $0.0001-1$ are written in each plot

of the residual values were calculated between the original solution and the noisy solutions. These results are shown in Fig. 6. As expected, the north deformation component has the lowest precision (i.e., the highest sensitivity to noise in the input data) and the vertical deformation component has the highest precision (i.e., lowest sensitivity to noise in the input data). Models describing the linear fit between the noise in the input data and the noise in the output data have very high coefficients of determination $R^{2}$ ranging from 0.83 to $\sim 1.00$.

Assuming that the precision of the original interferograms is about $0.005 \mathrm{~m}$ gives a precision of north, east and vertical deformation rate components of approximately is $0.47,0.07$, and $0.06 \mathrm{~m} /$ year, respectively. The horizontal deformation rate vector map (Fig. 5g) shows a consistent flow pattern, suggesting that the measurement precision is indeed high.

The systematic error produced by the non-steady-state flow also cannot be directly estimated. To better understand the impact of the non-steady-state flow on computed deformation rates, a synthetic test was performed, as follows. It was assumed that $V_{u}^{\text {nss }}$ is linearly dependant on glacier elevation only where this dependence can be esti- mated approximately from data provided in Fig. 4 of Abdalati et al. (2004), which shows elevation change rate measured by the repeated airborne laser surveys over the Barnes Ice Cap. The estimated elevation change rate model was added to (5), and deformation rates were computed. While the vertical deformation rate map showed a consistent deformation pattern, with the rate equal to the elevation change rate due to the non-steady-state motion and the surface-parallel flow, the horizontal deformation rates showed an asymmetric pattern across the ice cap, suggesting that our DInSAR data give no confirmation of the non-steady-state deformation regime. Indeed, Gray et al. (2015) showed using CryoSat-2 data that the Barnes Ice Cap experiences large elevation changes during May-September period and remains in the steady state (within measurement error) during the remainder of the year.

\section{Discussion}

The assumption of negligible north deformation component is not applicable to the glacier ice flow investigated in this 


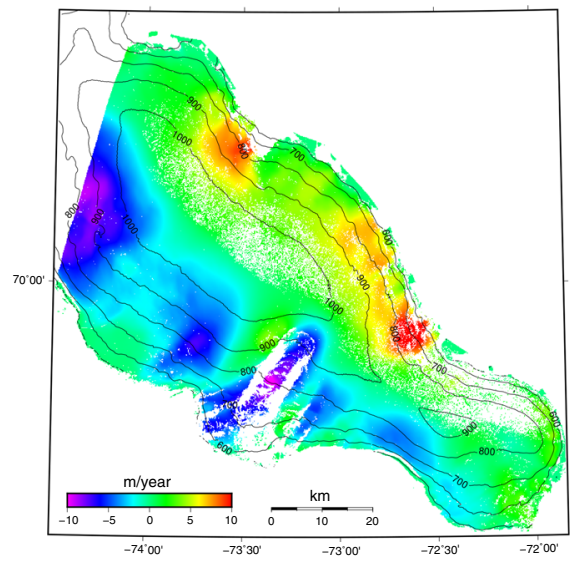

(a) East deformation component

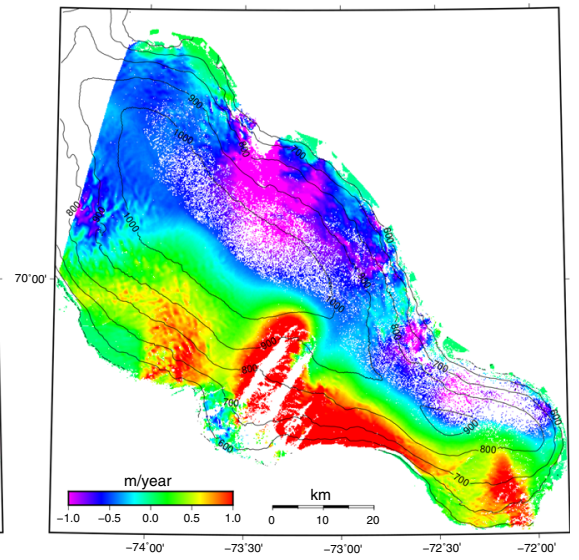

(b) Vertical deformation component

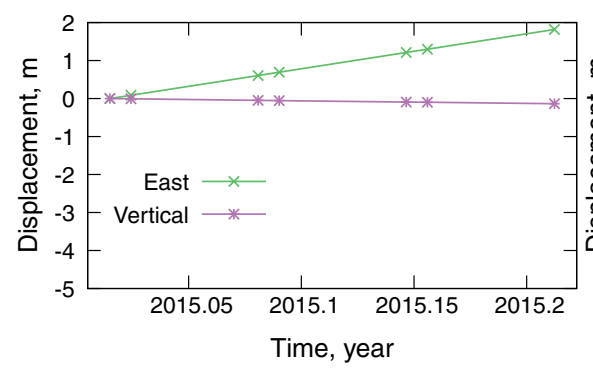

(c) Deformation time series of P1

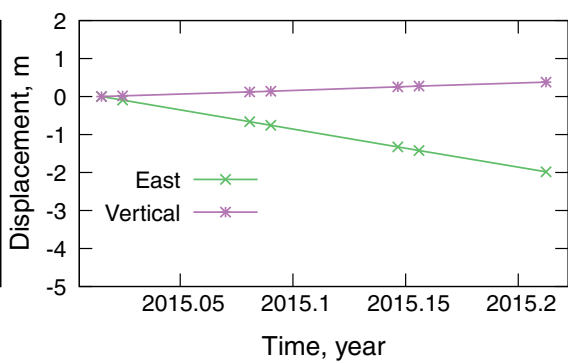

(d) Deformation time series of P2

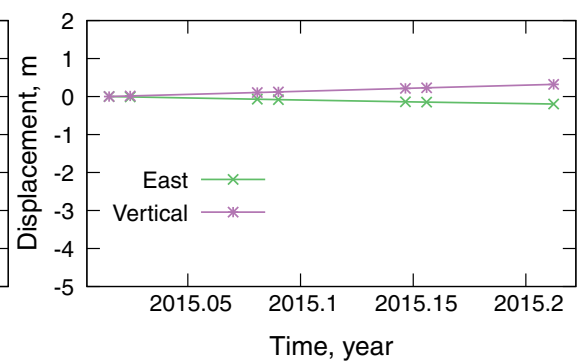

(e) Deformation time series of P3
Fig. 4 Computed with MSBAS-2D from RADARSAT-2 ascending and descending DInSAR data linear deformation rate maps of east (a) and vertical (b) components; 100-m elevation contour lines are plotted in black. Two-dimensional deformation time series for selected points P1 (c), P2 (d) and P3 (e), which locations are shown in a, b. R is reference region study. Indeed, at the Barnes Ice Cap during January-March 2015 , the maximum north deformation rate exceeds the maximum vertical deformation rate by about a factor of 10 (Fig. 4). Therefore, the contribution of the north component to DInSAR is about $\frac{10 \sin \theta \sin \phi}{\cos \phi}=1.75$ times larger than the contribution of the vertical component. The MSBAS3D technique that utilizes the SPF constraint and solves for north, east and vertical deformation components produces superior results compared to a $2 \mathrm{D}$ approach solving for east and vertical deformation components only.

For static cases, the SPF assumption was used in (Joughin et al. 1998) for computing 3D deformation of Ryder glacier, Greenland, and in (Kumar et al. 2011) of Himalayan glaciers. The accuracy of this approach was validated in (Mohr et al. 1998) for Storstrommen glacier, Greenland, by comparing DInSAR derived results computed under the SPF assumptions with GPS measurements, and in (Gourmelen et al. 2011) for the Langjökull and Hofsjökull ice caps by comparing with MAI measurements. However, in (Reeh et al. 1999) it was shown that the SPF assumption can be applied only to glaciers in a steady state. Hence, for the case of non-steady-state flow and when the elevation change rate is known, modified MSBAS-3D technique (5) can be used. The precision of east and vertical deformation components computed with MSBAS-3D is higher than the precision of north deformation component.

The first central derivatives along the north and east directions are computed from DEM. In the case of a highresolution DEM, the derivative maps also are of a high resolution, displaying surface features that do not necessarily contribute to the motion. To avoid this effect spatial smoothing of DEM prior to computing derivatives may be necessary, which needs to be further investigated.

The maximum observed vertical deformation rate at the Barnes Ice Cap during January-March 2015 is about 3 $\mathrm{m} /$ year, while the average rate is only about $0.09 \mathrm{~m} / \mathrm{year}$. In (Gray et al. 2015) using CryoSat-2 measurements the average summer elevation decreases were estimated to be $2.05 \pm 0.36 \mathrm{~m}$ (2011), $2.55 \pm 0.32 \mathrm{~m}$ (2012), $1.38 \pm 0.40 \mathrm{~m}$ (2013) and $1.44 \pm 0.37 \mathrm{~m}$ (2014), while the winter-to-winter net elevation losses were $1.0 \pm 0.20 \mathrm{~m}$ (winter $2010 / 11$ to winter 2011/12), $1.39 \pm 0.20 \mathrm{~m}(2011 / 12$ to 2012/13) and $0.36 \pm 0.20 \mathrm{~m}(2012 / 13$ to $2013 / 14)$, for a total surface elevation loss of $2.75 \pm 0.20 \mathrm{~m}$ over the 3 -year period. Since only a three-month period is covered by this study, during which the Barnes Ice Cap remains in the steady state, the 


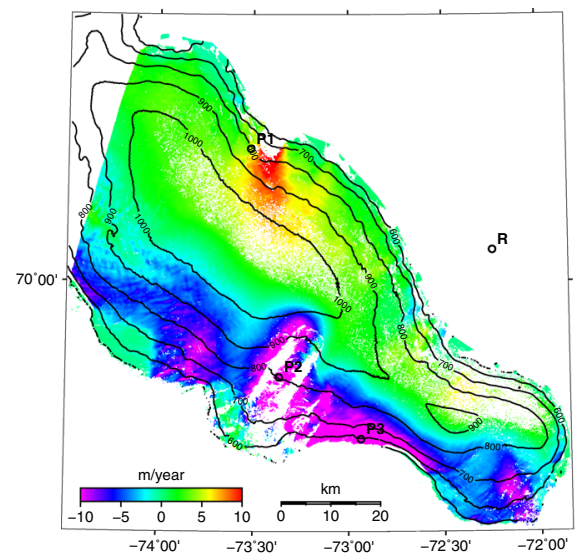

(a) North deformation component

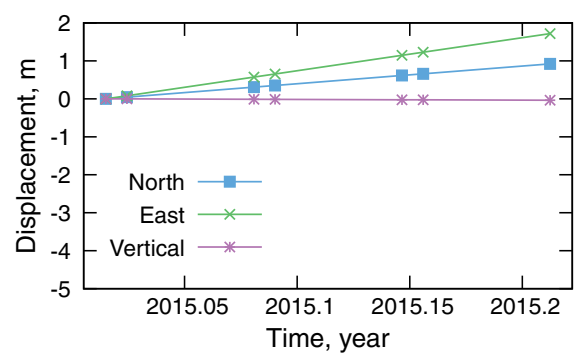

(d) Deformation time series of P1

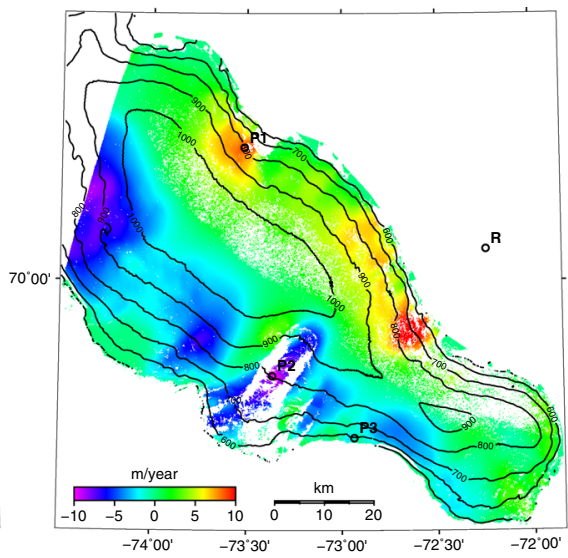

(b) East deformation component

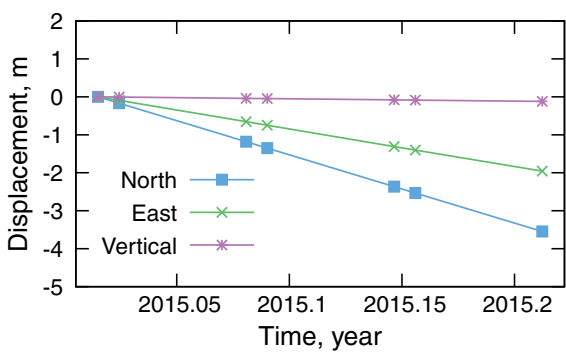

(e) Deformation time series of P2



(c) Vertical deformation component

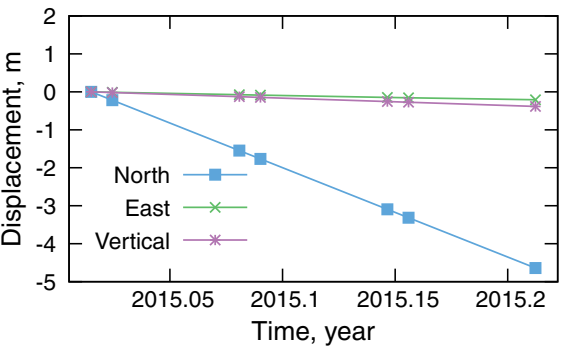

(f) Deformation time series of P3

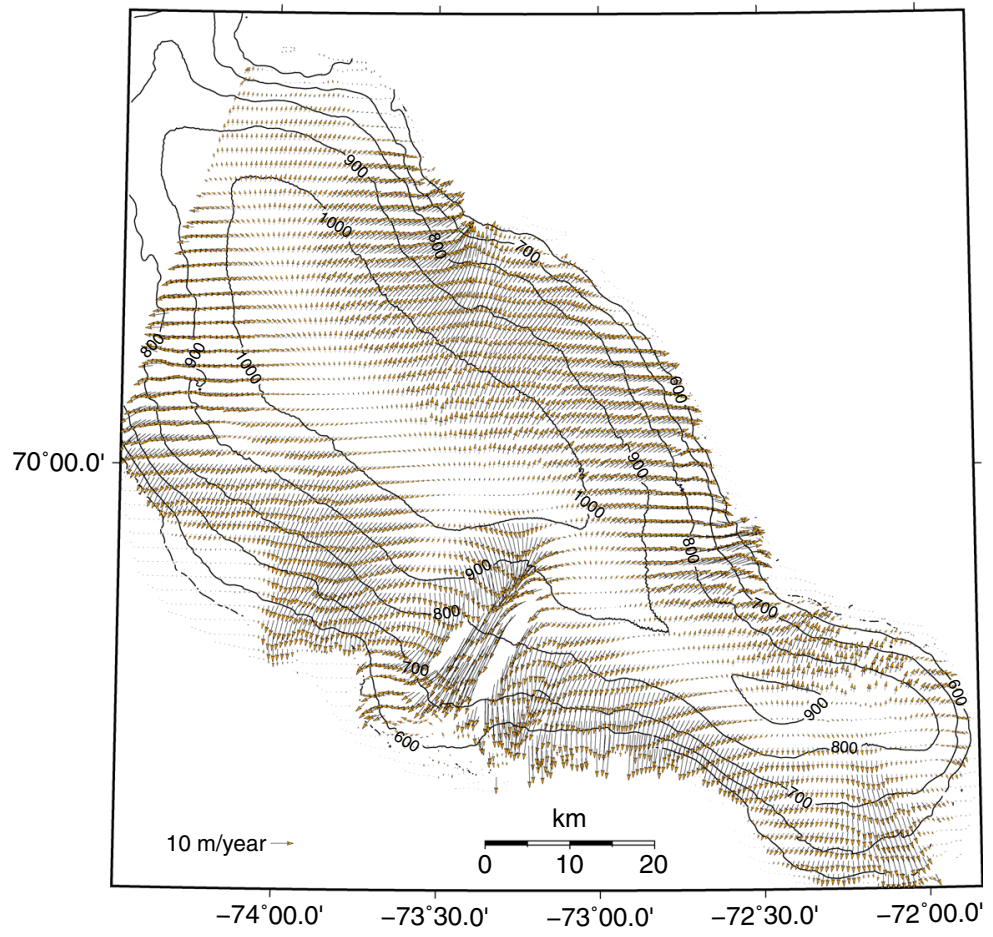

(g) Horizontal deformation rate vector map

Fig. 5 Computed with MSBAS-3D from RADARSAT-2 ascending and descending DInSAR data linear deformation rate maps of north (a), east (b) and vertical (c) components; 100-m elevation contour lines are plotted in black. Three-dimensional deformation time series for selected points P1 (d), P2 (e) and P3 (f), which locations are shown in a-c. $\mathrm{R}$ is reference region. Horizontal deformation rate vector map ( $\mathrm{g}$ ) is computed by combining north and east components 


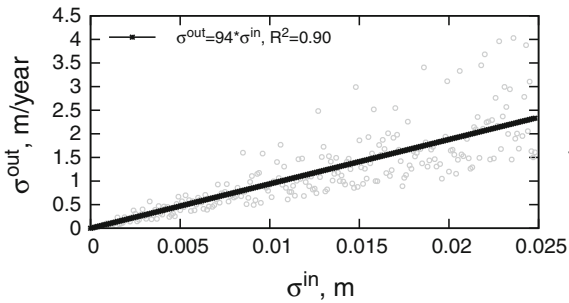

(a) North deformation component

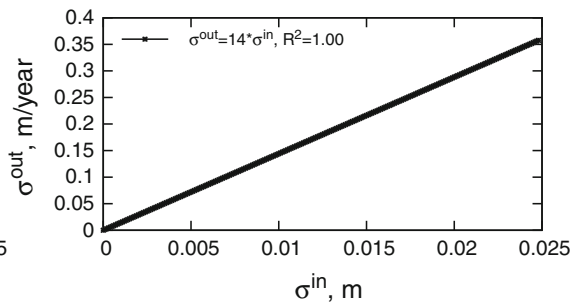

(b) East deformation component

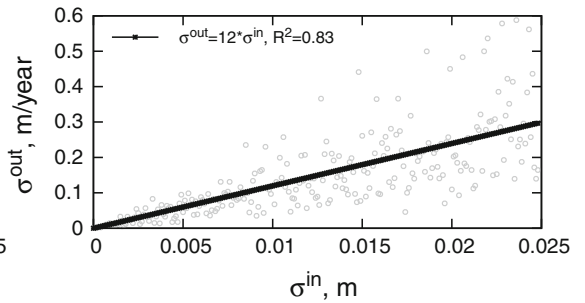

(c) Vertical deformation component

Fig. 6 Precision of computed linear deformation rates as function of precision of individual interferograms

direct comparison of MSBAS-3D derived results from this study and the CryoSat-2 derived results from (Gray et al. 2015) is not feasible. The MSBAS-3D computations, however, provide high-resolution horizontal velocities during the January-March period that cannot be measured otherwise.

\section{Conclusion}

The novel MSBAS-3D technique computes the constrained 3D deformation time series from several ascending and descending DInSAR data sets. The main assumption of this technique is that motion occurs parallel to the surface, driven by the gravitational force with no internal deformation. This technique is used for computing $3 \mathrm{D}$ deformation at the Barnes Ice Cap (Baffin Island, Nunavut, Canada) during January-March 2015.

The availability of SAR data plays an important role in determining which techniques can be used for studying glacier flow. Sparse data collected at a single geometry and orbit direction allow computation of individual interferograms. Interferometry is not particularly suitable for fast glaciers, which makes phase analysis impossible in areas of fast flow. Speckle tracking will therefore remain an important component in glacier monitoring. The Barnes Ice Cap study shows relatively slow movement (a few tens of meters per year), so speckle tracking would therefore have large uncertainties or require acquisitions with longer time separation.

MSBAS-3D technique can be used for mapping ice flow at other glaciers and other surface deformation processes with large north deformation component, such as landslides. This technique can be successfully utilized for processing of very large data sets collected by the rapid revisit SAR satellites, such as Sentinel-1 (6-day revisit period) and the forthcoming RADARSAT Constellation Mission (4-day revisit period). Interferograms acquired by the rapid revisit satellites exhibit better interferometric coherence and are preferable for mapping glacier motion. The software implementation of MSBAS-3D technique can be downloaded from http://insar.ca/.
Acknowledgements The author would like to thank the Canadian Space Agency (CSA) for providing RADARSAT-2 data; George Choma for the internal and Jonathan Normand for the external reviews. Figures were plotted with GMT and GNUPLOT software. The test set, consisting of processed RADARSAT- 2 interferograms, and the processing software can be downloaded from the author's Web site http://insar.ca.

Open Access This article is distributed under the terms of the Creative Commons Attribution 4.0 International License (http://creativecomm ons.org/licenses/by/4.0/), which permits unrestricted use, distribution, and reproduction in any medium, provided you give appropriate credit to the original author(s) and the source, provide a link to the Creative Commons license, and indicate if changes were made.

\section{References}

Abdalati W, Krabill W, Frederick E, Manizade S, Martin C, Sonntag J, Swift R, Thomas R, Yungel J, Koerner R (2004) Elevation changes of ice caps in the Canadian Arctic Archipelago. J Geophys Res Earth Surf. https://doi.org/10.1029/2003JF000045

Czarnogorska M, Samsonov S, White D (2016) Airborne and spaceborne remote sensing characterization for Aquistore carbon capture and storage site. Can J Remote Sens. https://doi.org/10.1080/ 07038992.2016.1171131

Fuhrmann T, Garthwaite MC (2019) Resolving three-dimensional surface motion with InSAR: constraints from multi-geometry data fusion. Remote Sens 11(3):241. https://doi.org/10.3390/ rs 11030241

Gilbert A, Flowers GE, Miller GH, Rabus BT, Van Wychen W, Gardner AS, Copland L (2016) Sensitivity of Barnes Ice Cap, Baffin Island, Canada, to climate state and internal dynamics. J Geophys Res Earth Surf 121:1516-1539. https://doi.org/10.1002/ 2016JF003839

Gourmelen N, Kim SW, Shepherd A, Park JW, Sundal AV, Björnsson H, Pálsson F (2011) Ice velocity determined using conventional and multiple-aperture InSAR. Earth Planet Sci Lett 307(1-2):156-160. https://doi.org/10.1016/j.epsl.2011.04.026

Gray L (2011) Using multiple RADARSAT InSAR pairs to estimate a full three-dimensional solution for glacial ice movement. Geophys Res Lett. https://doi.org/10.1029/2010GL046484

Gray L, Burgess D, Copland L, Demuth MN, Dunse T, Langley K, Schuler TV (2015) CryoSat-2 delivers monthly and inter-annual surface elevation change for Arctic ice cap. Cryosphere 9:18951913. https://doi.org/10.5194/tc-9-1895-2015

Hansen P, O'Leary D (1993) The use of the L-curve in the regularization of discrete ill-posed problems. SIAM J Sci Comput 14(6):14871503

Hu J, Li ZW, Ding XL, Zhu JJ, Zhang L, Sun Q (2014) Resolving three-dimensional surface displacements from InSAR measure- 
ments: a review. Earth Sci Rev 133:1-17. https://doi.org/10.1016/ j.earscirev.2014.02.005 (ISSN: 0012-8252)

Jo M-J, Jung H-S, Yun S-H (2017) Retrieving precise three-dimensional deformation on the 2014 M6.0 South Napa earthquake by joint inversion of multi-sensor SAR. Sci Rep 7(1):5485. https://doi.org/ 10.5194/isprs-archives-XLII-3-57-2018

Joughin IR, Kwok R, Fahnestock MA (1998) Interferometric estimation of three-dimensional ice-flow using ascending and descending passes. IEEE Trans Geosci Remote Sens 36(1):25-37. https://doi. org/10.1109/36.655315

Kumar V, Venkataramana G, Høgda KA (2011) Glacier surface velocity estimation using SAR interferometry technique applying ascending and descending passes in Himalayas. Int J Appl Earth Obs Geoinform 13(4):545-551. https://doi.org/10.1016/j.jag.2011.02. 004

Liu J-H, Hu J, Li Z-W, Zhu J-J, Sun Q, Gan J (2018) A method for measuring 3-D surface deformations with InSAR based on strain model and variance component estimation. IEEE Trans Geosci Remote Sens 1(56):239-250. https://doi.org/10.1109/tgrs.2017.2745576

Manzo M, Ricciardi G, Casu G, Ventura F, Zeni G, Borgstrom S, Berardino P, Del Gaudio C, Lanari R (2006) Surface deformation analysis in the Ischia Island (Italy) based on spaceborne radar interferometry. J Volcanol Geotherm Res 151:399-416

Mohr JJ, Reeh N, Madsen SN (1998) Three-dimensional glacial flow and surface elevation measured with radar interferometry. Nature 391:273-276. https://doi.org/10.1038/34635

Motagh M, Shamshiri R, Haghshenas Haghighi M, Wetzel H-U, Akbari B, Nahavandchi H, Roessner S, Arabi S (2017) Quantifying groundwater exploitation induced subsidence in the Rafsanjan plain, southeastern Iran, using InSAR time-series and in situ measurements. Eng Geol 218:134-151. https://doi.org/10.1016/ j.enggeo.2017.01.011

Palanisamy Vadivel SK, Kim D-J, Jung J, Cho Y-K, Han K-J, Jeong K-Y (2019) Sinking tide gauge revealed by space-borne InSAR: Implications for sea level acceleration at Pohang, South Korea. Remote Sens 11(3):277. https://doi.org/10.3390/rs11030277

Raucoules D, de Michele M, Malet J-P, Ulrich P (2013) Time-variable 3D ground displacements from high-resolution synthetic aperture radar (SAR). Application to La Valette landslide (South French Alps). Remote Sens Environ 139:198-204. https://doi.org/ 10.1016/j.rse.2013.08.006

Reeh N, Madsen SN, Mohr JJ (1999) Combining SAR interferometry and the equation of continuity to estimate the three-dimensional glacier surface-velocity vector. J Glaciol 45(151):533-538. https:// doi.org/10.3189/S0022143000001398

Rignot E, Mouginot J, Scheuchl B (2011) Ice flow of the Antarctic ice sheet. Science 333(6048):1427-1430. https://doi.org/10.1126/ science.1208336 (ISSN: 0036-8075)

Samsonov S (2010) Topographic correction for ALOS PALSAR interferometry. IEEE Trans Geosci Remote Sens 48(7):3020-3027

Samsonov S, d'Oreye N (2012) Multidimensional time series analysis of ground deformation from multiple InSAR data sets applied to Virunga Volcanic Province. Geophys J Int 191(3):1095-1108. https://doi.org/10.1111/j.1365-246X.2012.05669.x

Samsonov SV, d'Oreye N (2017) Multidimensional small baseline subset (MSBAS) for two-dimensional deformation analysis: case study Mexico City. Can J Remote Sens. https://doi.org/10.1080/ 07038992.2017.1344926

Samsonov S, d'Oreye N, Smets B (2013a) Ground deformation associated with post-mining activity at the French-German border revealed by novel InSAR time series method. Int J Appl Earth Obs Geoinform 23:142-154. https://doi.org/10.1016/j.jag.2012. 12.008

Samsonov S, Gonzalez PJ, Tiampo K, d'Oreye N (2013b) Spatiotemporal analysis of ground deformation occurring near Rice Lake, Saskatchewan, and observed by Radarsat-2 DInSAR during 20082011. Can J Remote Sens 39(1):27-33. https://doi.org/10.5589/ m13-005

Samsonov S, d'Oreye N, González P, Tiampo K, Ertolahti L, Clague J (2014a) Rapidly accelerating subsidence in the Greater Vancouver region from two decades of ERS-ENVISAT-RADARSAT-2 DInSAR measurements. Remote Sens Environ 143(5):180-191. https://doi.org/10.1016/j.rse.2013.12.017

Samsonov S, Gonzalez P, Tiampo K, d'Oreye N (2014b) Modeling of fast ground subsidence observed in southern Saskatchewan (Canada) during 2008-2011. Nat Hazards Earth Syst Sci 14:247257. https://doi.org/10.5194/nhess-14-247-2014

Samsonov SV, Tiampo KF, Camacho AG, Fernández J, González PJ (2014c) Spatiotemporal analysis and interpretation of 1993-2013 ground deformation at Campi Flegrei, Italy, observed by advanced DInSAR. Geophys Res Lett 41(17):6101-6108. https://doi.org/10. 1002/2014GL060595

Samsonov SV, Trishchenko AP, Tiampo K, González PJ, Zhang Y, Fernández J (2014d) Removal of systematic seasonal atmospheric signal from interferometric synthetic aperture radar ground deformation time series. Geophys Res Lett 41(17):6123-6130. https:// doi.org/10.1002/2014GL061307

Samsonov S, Czarnogorska M, White D (2015) Satellite interferometry for high-precision detection of ground deformation at a carbon dioxide storage site. Int J Greenh Gas Control 42:188-199. https:// doi.org/10.1016/j.ijggc.2015.07.034

Samsonov SV, Lantz TC, Kokelj SV, Zhang Y (2016a) Growth of a young pingo in the Canadian Arctic observed by RADARSAT2 interferometric satellite radar. The Cryosphere 10(2):799-810. https://doi.org/10.5194/tc-10-799-2016

Samsonov SV, Tiampo KF, Feng W (2016b) Fast subsidence in downtown of Seattle observed with satellite radar. Remote Sens Appl Soc Environ 4:179-187. https://doi.org/10.1016/j.rsase.2016.10. 001

Samsonov SV, Feng W, Peltier A, Geirsson H, d'Oreye N, Tiampo KF (2017) Multidimensional Small Baseline Subset (MSBAS) for volcano monitoring in two dimensions: opportunities and challenges. Case study Piton de la Fournaise volcano. J Volcanol Geotherm Res 344:121-138. https://doi.org/10.1016/j.jvolgeores.2017.04.017

Wang Z, Zhang R, Wang X, Liu G (2018) Retrieving three-dimensional co-seismic deformation of the 2017 Mw7.3 Iraq earthquake by multi-sensor SAR images. Remote Sens 6(10):857. https://doi.org/ $10.3390 /$ rs 10060857

Yang Z, Li Z, Zhu J, Feng G, Wang Q, Hu J, Wang C (2018) Deriving time-series three-dimensional displacements of mining areas from a single-geometry InSAR dataset. J Geod 92:529-544. https://doi. org/10.1007/s00190-017-1079-x 